\title{
Strategy and Mechanism For Driving To Success In Research; Case Study Khon Kaen University, Thailand
}

\author{
Chusorn Prayuth ,Ed.D. \\ Educational Administration Department, Faculty of Education, Khon Kaen University Thailand
}

\begin{abstract}
The objective of this research was to study strategy and mechanism for driving to success in research of Khon Kaen University, to be effective research university through 3 phases of Policy Research. For research findings, 3 aspects of strategies and mechanisms were found : the product, research environment, and recognition in research. Each aspect was associated with 3 tasks as: the instruction, budget resource and staff management, and research management. Since the strategies and mechanisms would be accepted and practiced. Khon Kaen University should enhancing the participatory working climate and culture in order to accomplish the state of sustainable research university existing in various levels of administrators and practitioners truly and extensively.
\end{abstract}

Keywords: strategy and mechanism, policy research, research environment, recognition in research, Research University

\section{Introduction}

This paper aims to present. The research policy. Qualitative data synthesis and critical.

As well as to the dissemination of research to be clear to both national and international scholars. Details are as follows.Quality in one country, the United States with all its institutional mechanisms for evaluating research, is difficult, imagine the complexity of international comparisons. In the end, there appears to be only one coin of the realm for international research comparisons: the publication, and in most cases, the publication in a significant peer reviewed scientific journal. (Capaldi, 2010) From the past until now, higher education development in Thailand was expanded its context very much. The challenge of Thai Higher Education System was development of university which would lead to overcoming the crisis problem from low quality in higher education to excellent quality in higher education expected in future: to make the product and outcome of Educational Management in higher education be satisfied by students, people, society as stakeholders I over to be congruent with direction of national development. (Office of Higher Education Commission, 2008) According to Educational Reform in the past decade, it was necessary for the universities to change their contexts into educational institutions creating quality culture to exist in university organizations as well as a part of working lifestyle. (Wichai Tansiri, 2006) by encouraging the higher educational institutions to study how to develop quality of Educational Management into universal standard. Focusing on development of competency in conducting research was an important factor affecting the production of quality human resource, as well as the improvement in research product and innovation as major basis to elevate competency level of competition and potentiality of country in overall. (Krisanapong Keeratikon, 2009) It affected the government to establish emergent policy for the Office of Higher Education Commissions to emergently develop National Research Universities into International level in order to encourage Thailand to be center of studying the Research and Development as well as Training/academic conference in Regional level. Those policies were congruent with long range 15 years in Higher Education Framework Plan, $2^{\text {nd }}$ Issue (2008-2022) including guidelines for classifying Thai Universities into 4 groups as: 1) the Research University and Graduate Study College, 2) the Science and Technology University and Comprehensive University, 3) the four years University and Art University, and 4) the Community College.

Khon Kaen University was a university founded in 1964 as the first university in North Eastern Region, situated in region with the most area and population approximately $1 / 3$ of Thailand. It was the area facing problem of poverty as well as underprivileged during that time. It is still facing that problem until now. The establishment of university was to aim at participation in development of North Eatsern Region as shown in the speech of His Royal Highness the Majesty the King on the day opening Khon Kaen University on $20^{\text {th }}$ December 1967 at Khon Kaen University, an excerpt :

"Establishing one more university is very worthy since it would cause High Education Level to extend into Regional area. The most important thing of one part of the country. In future, it would provide good effect on development in upgrading livelihood of people in this region very much. Consequently, the success of establishing Khon Kaen University, is a success which every should be pleased with."(Work Planning Department, Khon Kaen University, 2008) 
Development of Khon Kaen University was performed respectively. Started from University in specific area in Science and Technology, extended into complete university offering instruction in Bachelor's Degree covering every field of study. It also was stepping into a Research University as well as Graduate Study. In the present, Khon Kaen University specifies its vision based on long range plan of Khon Kaen University 2009-2024 "Khon Kaen University is a Research University in Asia focusing on developing the Regional into sustainable development including management on the basis of good governance with human resource as a center of development." According to this specified vision, the active trend was stimulated for every level of Khon Kaen University Staffs, in amidst of implementation on various activities. Moreover, the research in searching for strategy and mechanism to change the strategy into an effective practice, was an important and necessary activity.

\section{Significance of the Study}

\section{Headings}

Management Principle based on viewpoints of Drucker (1999); Hoy and Miskel (2001); Lussier and Achua (2007); Owens (2001); Razik and Swanson (2001); Robbins and Coulter (1996); Rue and Byars (2007); Schermerhorn, (2008) etc. emphasizing on "doing the right thing." So that the work implementation would be in right direction without getting lost or wasting resource worthlessly regarding to man, money, material, and management. Therefore, searching for strategy as well as mechanism in transforming the strategy into effective practice by research process, would affect the implementation of Khon Kaen University in the right direction economically, usefully, and costly.

\section{Purpose:}

To study strategy and mechanism for driving into success in research of Khon Kaen University in order to accomplish the state of being effective research university based on expected vision to be a research university in Asia aiming to develop the region into universal level, create value to sustainable development, administer on basis of good governance, and include human resource as center of development.

\section{Method:}

In this research, Policy Research was implemented (Walker, 1985 site Wirot Sanrattana, 2011) including 3 phases as follows:

Phase 1: Research for establishing tentative strategy and mechanism for driving to success in research of Khon Kaen University by conducting Documentary research including: the announcement, order, annual report, strategic plan, proceedings, and research related literature.

Phase 2: Investigating the Feasibility and Acceptance in tentative strategy and mechanism driving for success by In-depth Interview from 5 experts in strategic management, 10 University Council Committees, 17 University Administrators, and 34 Instructors from different Faculties.

Phase 3: Confirmative Investigation by workshop seminar for the stakeholders including: representatives of parents, administrators, instructors, action staffs, students, an alumni based on spreading from different Faculties, 30 persons.

\section{Delimitation of the study}

According to documentary research in Phase 1, it consisted of the the announcement, order, annual report, strategic plan, proceedings, and research related literature, the researcher specified the delimitation of research as follows:

1) Dimension of strategy and mechanism for driving to success for 3 aspects: 1.1) the product, 1.2) the research environment, and 1.3) the recognition in research. Each aspect was associated with 3 tasks as: the instruction, budget resource and staff management, and research management. Since the strategies and mechanisms would be accepted and practiced.

2) Dimension of effectiveness in 5 aspects of research consisted of (1) the Performances were published and referenced, (2) performances were published in international level per instructors, (3) patent with the right to publish both of inside and outside the country, (4) research findings with high impact factor, and (5) construction in new body of knowledge which was up to date and more intensive.

\section{Conclusion}

According to research findings, found that the strategy and mechanism for driving to success of Khon Kaen University for being an effective research university in each aspect as follows:

1. The output/ outcomes

Strategies 
(1) Enhancing and supporting the conference to be held for preparing the staffs' readiness in every division or section relating to inside of Faculty. Every division collaborated in determining the strategies of implementation in each academic year and fiscal year so that the implementation would accomplish specified goal systematically for both of efficiency and effectiveness.

(2) Enhancing and supporting the instructors, staffs, and researchers to use various models in producing their research studies, creating performance for dissemination as well as being able to utilize the research findings efficiently.

(3) Monitoring, following up, and encouraging the research groups continuously. The research articles were obtained to be published in journals both of national level, and international level annually. The supportive group line collected data in data base to be used in report writing, internal auditing, and certifying the external audit of work offices in order to elevate the KPI for work offices.

(4) Brainstorming for setting system and mechanism in using intellectual property for developing into commercial work more by giving an importance to registering the patent or mini patent and stimulating the research instructors producing creative product in order to propose for registering the patent regularly.

\section{Mechanism for driving to success}

(1)The research findings or creative work being established or disseminated in national or international level for instructor and researchers.

(2) The research studies or creative works utilizing for instructor and researchers.

(3) Research articles being referenced in national or international level per total number of articles.

(4) References in national or international journal per total number of article.

(5) The research findings or creative work were registered for patent or mini patent per instructors or researchers.

\section{The environment}

\section{Strategies}

(1) Developing the structure of research management system including policy to set up research grant to support in conducting research, creating the academic performance in order to motivate the various groups of researcher to have morale in producing the increased number of research studies as well as creative work continuously.

(2) Giving an importance in producing research studies by allocating research budget for instructors, researchers, and graduate students.

(3)Developing the structure of research management system for constructing the useful body of knowledge, technology, and innovation by focusing on the needs of local and country.

(4)Constructing and developing the high potential researchers through learning management process as well as the senior researchers' experience.

(5)Encouraging the researcher to be able to conduct research completely in order to support policy of national research university, by grouping the instructors into the teaching oriented group, management oriented group, and research oriented group.

(6)Determining various implementation strategies, stimulating, supporting, creating research and development environment. Motivating the researcher groups for producing product regularly. Facilitating the basic factor of research for instructors, researchers, and graduate students in conducting research studies regularly.

\section{Mechanism for driving to success}

(1)Research project or creative work receiving grant from both of inside, and outside institute for instructors and researchers.

(2) The Grant for research or creative work receiving from both of inside, and outside institute for instructors and researchers.

(3)Instructors or researchers produced research studies or creative work continuously for instructors and researchers.

(4) Research climate

\section{The Esteem}

Strategies

(1) Encouraging the instructors, researchers and graduate students to produce outputs of research study, creative works to send for contest in different stage levels.

(2) Motivating in encouraging the research group to produce more research studies. The instructors or students could win the contest, obtain research reward from other work offices or institutions both in national, and 
international levels by providing money, honored certificate, and others to them as a morale in producing future research as well as honored the researchers.

\section{Mechanism for driving to success}

(1) The instructors and researchers who received reward for research or creative work per instructors and researchers.

(2) The sum of h-index of instructors and researchers, for the first 3 orders (Only Science and Technology Group, and Health Science).

(3) The number of instructors and researchers who were the leaders of integrated research project per instructors and researchers.

\section{Discussion And Recommendations}

According to research findings, found that the strategic issues in output/ outcomes gave an importance for preparing readiness of staffs from every division or section, to collaborate in determining strategies for implementation in each school/budget year, stimulated the research output/outcome as well as creative work for disseminating and utilizing the research findings efficiently, and brainstorming for putting the system as well as mechanism in using intellectual asset to develop the commercial work more by seeing an importance in registering patent or mini patent.

Owing to reasons caused by the changes in economic, social, and environment aiming to self-reliance, professional network, and long lasting happiness. So, it was research output/outcome relevant to objective as well as characteristic based on long plan framework, Khon Kaen University 2009-2024 specifying direction for developing Khon Kaen University in the long run for being congruent with direction of changes and development of higher education of the country as well as the world in future in order to be relevant to context of changes in both of Thai and Global Society. (Work Planning Department, Khon Kaen University, 2008)

It was also supported by Marakas ,G.'s (2012) statement that: Universities 21 st Century are the leading global network of research-intensive universities, working together to foster global citizenship and institutional innovation through research-inspired teaching and learning, student mobility, connecting our students and staff, and wider advocacy for internationalization.

In the research environmental condition, and esteem from research findings focusing on development of structure, research management system for constructing body of knowledge, technology, and innovation to be useful by emphasizing the excellence, serving to the needs of local and community, constructing and developing the high potential researcher in universal level trough process of Learning management as well as senior researchers' experience. It also included the environmental encouragement in research and development which might be due to Educational Quality Assurance System. The Educational Work Offices belonged to public sector or private sector in the present, gave an importance to the number of disseminated research studies or creative work in stage of academic seminar or article with impact factors in universal level. It was supported by standard criterion from both of THE-QS University Rankings (2010, and World University Rankings (2004)

According to the above research findings, the researcher viewed that in order to provide strategies and mechanisms to drive to success as a result of research studies, to be accepted, put into efficient and effective practice, Khon Kaen University should create "Participatory Working Climate and Culture to accomplish the sustainable research university," to be occurred with the administrators and practitioners in different levels truly and extensively.

\section{Acknowledgements}

This research report. Completely successful. It's by the grace and assistance of the executive and staff at the Khon Kaen University. As well as to transfer knowledge and skills. The process of acquiring knowledge. Be attributed to the study. Researcher will remember this day forever. And retain knowledge. Experiences.

Remembering the good things that have in. to life until you find it. All the knowledge gained. To distribute with other people anymore.

\section{Reference}

[1] Capaldi ,. (2010). The Top American Research Universities 2010 Annual Report .The Center for Measuring University Performance Retrieved July 19, 2012 from http://mup.asu.edu/research2010.

[2] Drucker, P.F. (1999). Management challenges for the 21st century. New York: Harper Collins.

[3] Hoy, W.K. \& Miskel, C.G. (2001). Educational administration: Theory, research, and practice. 6th ed. New York: McGraw-Hill.

[4] Keeratikon, Krisanapong. (2009). Crisis, Paradigm, Concept for Educational Reform.

Nondaburi: Wannakam Company Ltd.

[5] Lussier, R.N. \& Achua, C.F. (2007). Leadership: Theory, application, skill development. Ohio: South-Western College Publishing.

[6] Marakas ,G. (2012). U21 Research \& Projects Coordinator. Retrieved June 20,

2010, from http://www.universitas21.com/article/research/details/65/research- leaders-group 
[7] Office of Higher Education Commissions. (2008). 15 Years Long Range Plan of Higher Education Framework. $2^{\text {nd }}$ Issue (20082022). $3^{\text {rd }}$ Ed. Bangkok: Office.

[8] Owens, R.G. (2001). Organizational behavior in education: Instructional leadership and school reform. Boston: Allyn and Bacon.

[9] Razik, T.A. \& Swanson, A.D. (2001). Fundamental concepts of educational leadership. 2nd ed. New Jersey: Merrill Prentice-Hall.

[10] Robbins, S.P. \& Coulter, M. (1996). Management. 5th ed. New Jersey: Prentice Hall, International, Inc.

[11] Rue, L.W. \& Byars, L.L. (2007). Management: Skills and application. 12 th ed. New York: McGraw-Hill.

[12] Sanrattana, Wirot. (2011). Educational Management Research: Approach and Case Study. $2^{\text {nd }}$ Ed. Bangkok: Aksarapipat.

[13] Schermerhorn, J.R. (2008). Management. 9 th ed. NJ: John Wiley \& Sons, Inc.

[14] THE-QS University Rankings. (2010). QS Quacquarelli Symonds Limited. Retrieved June 20, 2010, from http://www.topuni versities.com/university-rankings/asian-university-rankings/methodology/asia-world

[15] Work Planning Department, Khon Kaen University. (2009). Long Range Plan Framework, Khon Kaen University. (2009-2023) Searching on $20^{\text {th }}$ July 2012 http://www.sc.kku.ac.th/UserFiles/File/Manage/Plan/PlanKKU_67.pdf

[16] World University Rankings. (2004). The Times Higher Education Supplement. Retrieved October 02, $2011 . \quad$ From http://www.thes.co.uk.worldrankings 